\begin{tabular}{lc}
\hline JOURNAL OF SCIENTIFIC PERSPECTIVES \\
ACADEMY \\
E-ISSN: $2587-3008$ \\
Attpril//ratingacademy.com.tr/journals/index.php/jsp/
\end{tabular}

\title{
SPECTROMETRIC DETERMINATION OF ROSUVASTATIN AND EZETIMIBE IN TABLETS BY MULTIVARIATE CALIBRATION APPROACH
}

Prof. Dr. Hakan AKTAŞ

Süleyman Demirel University, Faculty of Science and Arts, Chemistry Department, Isparta, Turkey,

E-mail: hakanaktas@sdu.edu.tr

Ms. Ümit UÇAR

Süleyman Demirel University, Faculty of Science and Arts, Chemistry Department, Isparta, Turkey

\begin{tabular}{|c|c|}
\hline ARTICLE INFO & ABSTRACT \\
\hline $\begin{array}{l}\text { Article History: } \\
\text { Received: } 19 \text { March } 2018 \\
\text { Accepted: } 28 \text { March } 2018\end{array}$ & \multirow{3}{*}{$\begin{array}{l}\text { Two multivariate calibration-prediction techniques, principal } \\
\text { component analysis (PCR) and partial least squares (PLS) were applied } \\
\text { to the spectrometric multicomponent analysis of the drug containing } \\
\text { rosuvastatin (ROS) and ezetimibe (EZE) without any separation step. } \\
\text { The selection of variables was studied. A series of synthetic solution } \\
\text { containing different concentrations of ROS and EZE were used to check } \\
\text { the prediction ability of the PCR and PLS. The results obtained in this } \\
\text { investigation strongly encourage us to apply these techniques for a } \\
\text { routine analysis and quality control of the two drugs. }\end{array}$} \\
\hline $\begin{array}{l}\text { Keywords: rosuvastatin, } \\
\text { ezetimibe, spectrometry, } \\
\text { multivariate calibration. }\end{array}$ & \\
\hline DOI: $10.26900 / j s p .2018 .8$ & \\
\hline
\end{tabular}

\section{INTRODUCTION}

Many drugs belonging to this class are registered with the Food and Drug Administration (FDA) and differ in terms of potency and pharmacological profile. One of them is rosuvastatin (ROS) (Figure 1b), which represents a new class of synthetic statins, with enantiomeric purity (Campo, Carvalho, 2007). Rosuvastatin ((3R,5S,6E)-7-[4-(4fluorophenyl)-6-(1-methylrthyl)-2-[methyl(methylsulfonyl)amino]-5-pyrimidinyl]-3,5dihydroxy-6-heptenoic acid) was approved in 2003 by the FDA and is sold by AstraZeneca as Crestor $^{\circledR}$. It is sparingly soluble in water and methanol and slightly soluble in ethanol. Some methods have been developed for the quantitation of rosuvastatin in pharmaceutical formulations (Ramadan, Mandil and Alshelhawil, 2014) developed a spectrophotometric method based on a derivatization reaction of rosuvastatin with iodine, as well as an electrochemical method based on differential pulse polarography using a dropping mercury electrode (Ramadan, Mandil, Ghazal, 2015). In addition, some methods based on chromatographic separation have also been proposed (Beludari, Prakash, Mohan, 2013).

Alzoman et al. (2013) and Wani et al. (2013) developed and applied a spectrophotometric method based on the charge transfer reaction between calcium rosuvastatin and $\pi$ acceptors. El-Bagary also proposed a method for the determination of this drug (El- 
Bagary, Elkady, Kadry,2012) in pharmaceutical preparations based on spectrophotometric determinations.

Ezetimibe (EZE) (Figure 1a) is also an oral antilipidaemic agent and is chemically 1-(4fluorophenyl) -(3R)- [3-(4 fluorophenyl)- 3S)-hydroxyphenyl]-4S-(4-hydroxyphenyl)-2azetidinone. It is not official in any pharmacopoeia. HPLC (Sistla RM, et al.,2005) and LC-MS (Kosoglu T et al., 2004) methods have been reported for the estimation of EZE in pharmaceutical formulations and in plasma. Also, HPLC (Shivshankar et al., 2007, Lingeswara Rao Punati et al., 2006) methods were reported for the simultaneous estimation of EZE in combined dosage forms.

In the present study, spectrophotometric method was suggested for direct and simultaneous determination of EZE and ROS using full-spectrum multivariate calibration methods, partial least-squares (PLS) and principal component regression (PCR) without any pre-separation step. The principal component regression (PCR) is a principal component analysis followed by a regression step. These methods are helpful chemometric techniques for the calculation of one component concentration in multicomponent mixtures. The offered methods are sensitive, simple, accurate, time saving, well-organized and are suitable for routine quality-control experiments. In this study, simultaneous determination and drug-dissolution monitoring was performed using PLS and PCR as most widely used multivariate calibration methods in binary mixtures of EZE and ROS as well as their combined tablet dosage form. It is noteworthy that simultaneous determination of EZE and ROS by the chemometrics-assisted methods has not been reported by other researchers.

a)

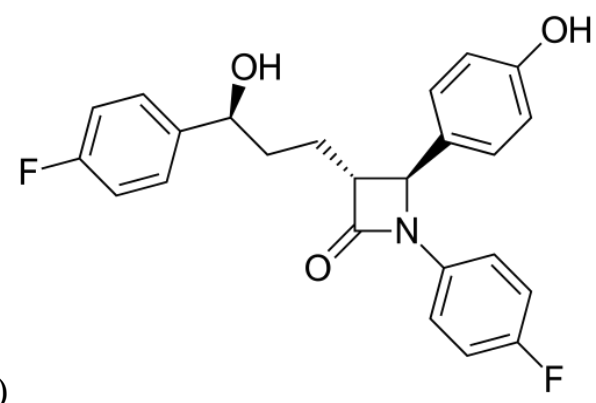

b)

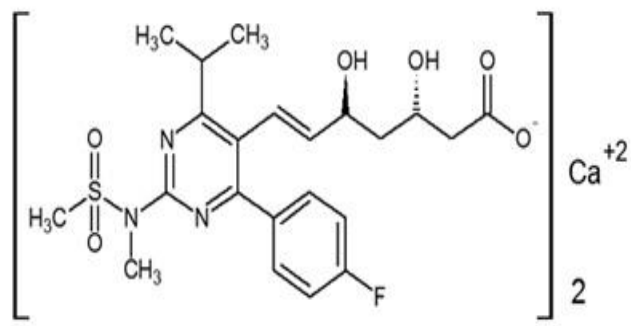

Figure 1. Structure of the drugs a) EZE b) ROS

The multivariate calibration techniques use full spectrum, full automation, multivariate data analysis and the reduction of noise and the advantages of the selection calibration model. In addition, these multivariate calibrations do not need any separation procedure, they are very cheap, very easy to apply and very sensitive. For these reasons these multivariate techniques are popular today.

In this study two chemometric methods were applied to analyse the synthetic mixtures and tablets consisting of EZE and ROS in the presence of interferences of the absorption spectra. The application of chemometrics allows the interpretation of multivariate data and is vital to the success of the simultaneous determination of the clinical drugs. 


\section{MATERIAL AND METHODS}

\subsection{Apparatus}

A Shimadzu (Model UV-1700) UV-Visible spectrometer (Shimadzu, Kyoto, Japan), equipped with $1 \mathrm{~cm}$ matched quartz cells was used for spectrometric measurements.

\subsection{Standard solutions}

All materials used were of analytical grade. Stock solutions of $10 \mathrm{mg} / 250 \mathrm{~mL}$ ROS and EZE were prepared in methanol. The solutions were stable for the least two weeks if they had been stored in a cool $\left(<25^{\circ} \mathrm{C}\right)$ and dark place.

\subsection{Pharmaceutical preparations}

The stock solution of clomipramine hydrochloride was diluted with ultra-pure-deionized water to obtain various clomipramine hydrochloride concentrations (changed concentrated to dilute). Under the optimum conditions described in the experimental section, a linear calibration plot was constructed in the clomipramine hydrochloride concentration range $5 \times 10^{-6}-3 \times 10^{-5} \mathrm{~mol} \mathrm{~L}^{-1}$. The repeatability, accuracy, and precision were determined.

\subsection{Procedure for dosage forms}

An accurately weighed pulverized tablets equivalent to $100 \mathrm{mg}$ of the studied drugs was extracted with $10 \mathrm{~mL}$ of $\mathrm{M}$ methanol, diluted with water, and sonicated for about $15 \mathrm{~min}$. The extracts were filtered into $100 \mathrm{~mL}$ volumetric flasks then washed and diluted to volume with distilled water. Aliquots these solutions were transferred into a series of $10 \mathrm{~mL}$ volumetric flasks and the analysis were completed as spectrometric procedure. All the techniques were applied to the final solution.

\subsection{Chemometrics Methods}

PLS and PCR are factor analysis method, based on a two stage procedure; a calibration step, in which a mathematical model is built by using component concentrations and spectral data from a set of references, followed by a prediction step in which the model is used to calculate the concentrations unknown sample from its spectrum. These methods are also called factor methods because they transform the original variables into a smaller number of orthogonal variables called factors or principal components (PCs), which are linear combinations of the original variables. When multivariate calibration approaches are applied in spectrophotometric multi component analysis, a relationship between spectral and concentration data from reference samples, representing the variables of the system, is established. A new matrix constituted by the new variables PCs and scores is built. The calculation of this new matrix is planned by algorithm specific to the regression method adopted. The major difference in the predictive abilities of these two methods is that PLS seems to predict better than PCR when there are random linear baselines or independently varying major spectral components which overlap with the spectral features of the analysis. The optimal of calibration method depend on the particular experimental conditions. However, PLS seems to a reasonable choice over a wide range of conditions.

\section{RESULTS AND DISCUSSION}

Figure 1 shows the absorption spectra for ROS and EZE and their mixture in methanol. 


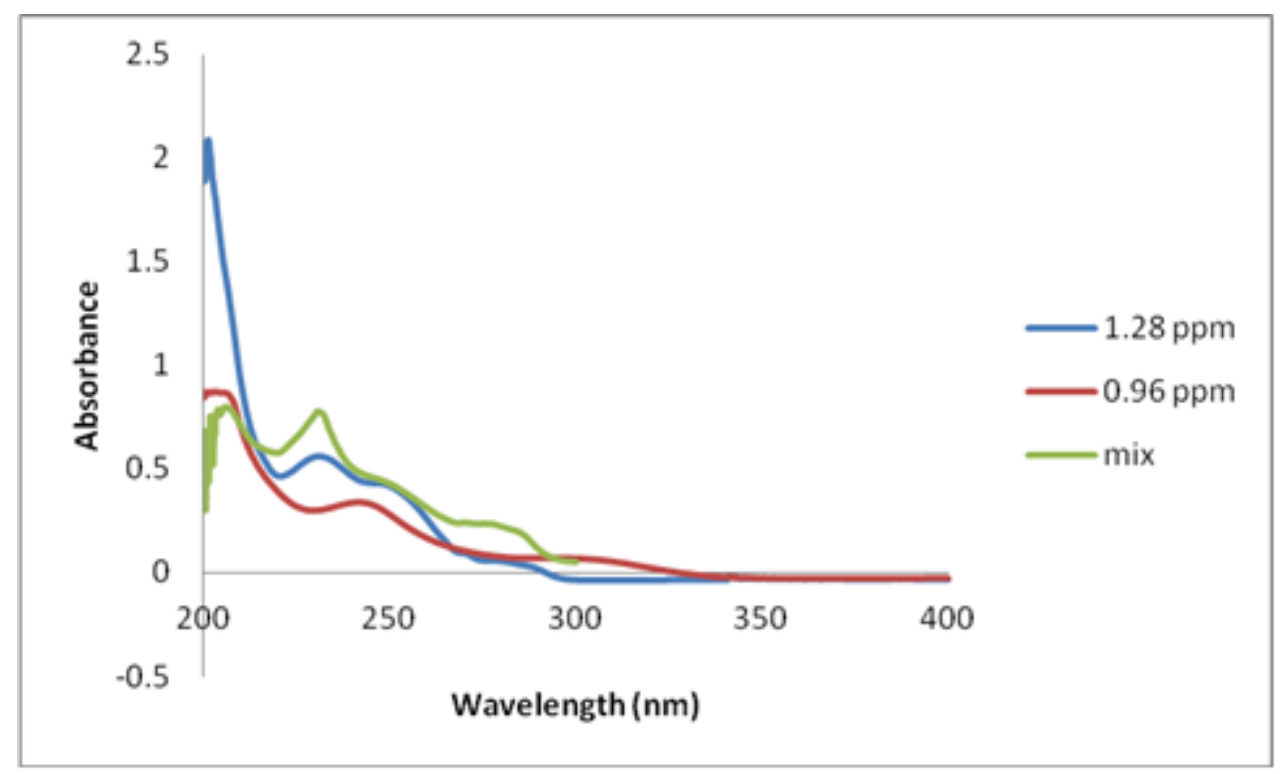

Figure1. Original absorption spectra of $1.28 \mu \mathrm{g} / \mathrm{mL}$ EZE $0.96 \mu \mathrm{g} / \mathrm{mL}$ ROS and their mixture in methanol

In order to build the two chemometric calibration, a training set was randomly prepared by using the standard mixture solution containing $0.48-0.96 \mu \mathrm{g} / \mathrm{mL}$ ROS and $0.32-1.60$ $\mu \mathrm{g} / \mathrm{mL}$ EZE in the variable proportions as shown in Figure 2.

The absorbance data matrix were obtained by measuring at the 13 wavelengths with the intervals $\Delta \lambda=5 \mathrm{~nm}$ in the $200-400 \mathrm{~nm}$ spectral region. The prepared calibrations of three techniques using the absorbance data sets were used to predict concentration of the unknown values of ROS and EZE in their mixture. Linearity range was $0.48-2.40 \mu \mathrm{g} / \mathrm{mL}$ for ROS and $0.64-3.20 \mu \mathrm{g} / \mathrm{mL}$ for EZE in the multivariate calibration proposed.

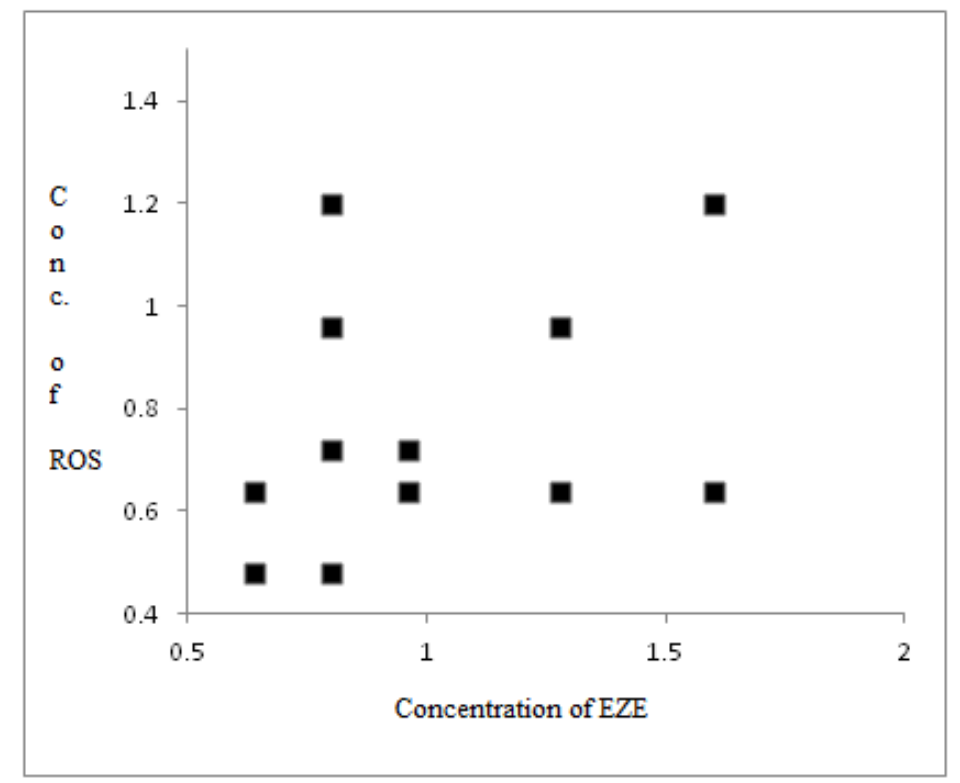

Figure 2. Concentration set design for the preparation of PCR and PLS calibrations 
A calibration for each technique was computed in the MINITAB 16.0 and PLS Toolbox 4.0 software by using set consisting of two drugs and their absorbance data. The multivariate calibrations of three techniques were used to predict the unknown concentrations of ROS and EZE in the samples.

Some statistical parameters were given for the validation of the constructed calibrations for the training set and synthetic binary mixtures of both drugs.

The application competence of a calibration model can be explained in several ways. We can also examine these results numerically. One of the best ways to do this by examining the predicted residual error sum-of-squares or PRESS. To calculate PRESS we compute the errors between the expected and predicted values for all the samples, square them, and sum them together.

$$
\text { PRESS }=\sum_{i=1}^{n}\left(C_{i}^{\text {added }}-C_{i}^{\text {found }}\right)^{2}
$$

Strikingly speaking, this is not a correct way to normalize the PRESS values when not all of the data sets contain the same number of samples. If we want correctly compare PRESS values for data sets that contain differing numbers of samples, we should convert to standard error of prediction (SEP), which is given by following formula.

$$
\mathrm{SEP}=\sqrt{\frac{\sum_{i=1}^{n}\left(C_{i}^{\text {added }}-C_{i}^{\text {found }}\right)^{2}}{n-1}}
$$

Where $C_{i}^{\text {added }}$ the added concentration of drug is, $C_{i}^{\text {found }}$ is the found concentration of drug and $\mathrm{n}$ is the total number of the synthetic mixtures. The SEP can provide a good measure of how well, on average, the calibration model performs. Often, however, the performance of the calibration model varies depending on the analyte level.

In the application of two chemometric techniques to the synthetic mixtures containing two drugs in variable compositions, the mean recoveries and relative standard deviations for PCR and PLS were found to be $99.98 \%, 0.01$ and $100.04 \%, 0.02$ respectively for EZE and $100.00 \%$ and $0.04,99.99 \%$ and 0.09 respectively for ROS (Table 1 and 2). 
Table 1. Results obtained for EZE and ROS indifferent synthetic mixtures by using PCR technique

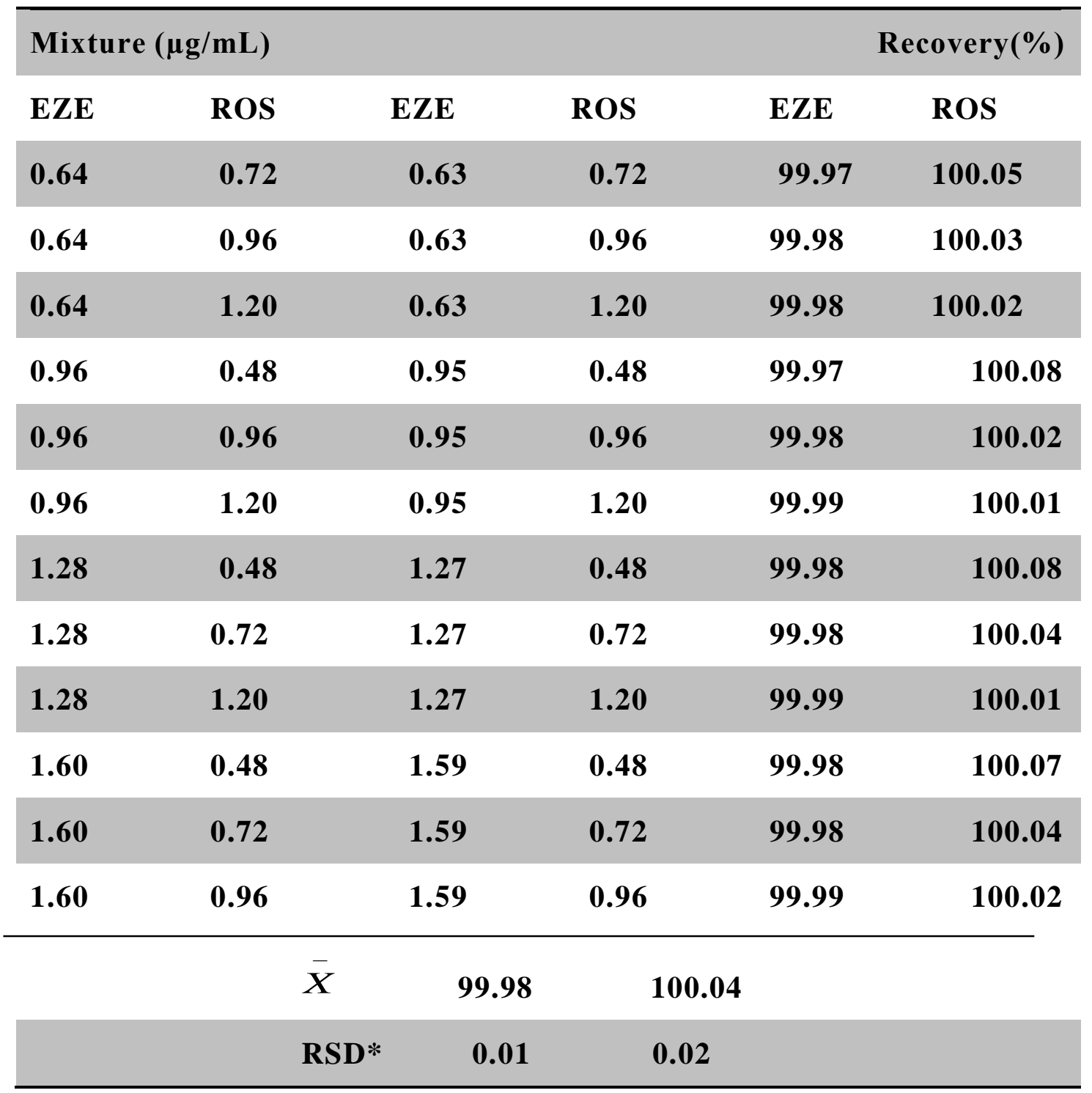


Table 2. Results obtained for EZE and ROS indifferent synthetic mixtures by using PLS technique

\begin{tabular}{|c|c|c|c|c|c|}
\hline \multicolumn{2}{|c|}{ Mixture $(\mu \mathrm{g} / \mathrm{mL})$} & \multirow[b]{2}{*}{ EZE } & \multirow[b]{2}{*}{ ROS } & \multicolumn{2}{|c|}{ Recovery(\%) } \\
\hline EZE & ROS & & & EZE & ROS \\
\hline 0.64 & 0.72 & 0.63 & 0.72 & 99.93 & 100.03 \\
\hline 0.64 & 0.96 & 0.64 & 0.95 & 100.07 & 99.95 \\
\hline 0.64 & 1.20 & 0.64 & 1.19 & 100.01 & 99.96 \\
\hline 0.96 & 0.48 & 0.95 & 0.48 & 99.97 & 100.04 \\
\hline 0.96 & 0.96 & 0.96 & 0.96 & 100.00 & 100.01 \\
\hline 0.96 & 1.20 & 0.96 & 1.20 & 100.01 & 100.07 \\
\hline 1.28 & 0.48 & 1.27 & 0.47 & 99.97 & 99.80 \\
\hline 1.28 & 0.72 & 1.28 & 0.71 & 100.06 & 99.83 \\
\hline 1.28 & 1.20 & 1.27 & 1.19 & 99.95 & 99.88 \\
\hline 1.60 & 0.48 & 1.60 & 0.48 & 100.00 & 100.08 \\
\hline 1.60 & 0.72 & 1.60 & 0.72 & 100.01 & 100.01 \\
\hline \multirow[t]{3}{*}{1.60} & 0.96 & 1.59 & 0.96 & 99.98 & 100.05 \\
\hline & & 100.00 & 99.99 & & \\
\hline & & RSD* & 0.09 & & \\
\hline
\end{tabular}

According to the added concentration and the concentration found in samples, the SEP and PRESS values of PCR and PLS techniques were calculated 8.99.10 $0^{-3}, 9.62 .10^{-3}$ and 1.21.10${ }^{3}, 1.38 .10^{-5}$ respectively for EZE, $1.90 .10^{-2}, 3.4 .10^{-2}$ and $5.45 .10^{-3}, 1.73 .10^{-4}$ respectively for ROS (Table 3). 
Table 3. Statistical parameters in the calibration-prediction

\begin{tabular}{llll}
\hline Parameter & Method & EZE & ROS \\
\hline PRESS & PCR & $1.21 .10^{-3}$ & $5.45 .10^{-3}$ \\
& PLS & $1.38 .10^{-5}$ & $1.73 .10^{-4}$ \\
SEP & PCR & $8.99 .10^{-3}$ & $1.90 .10^{-2}$ \\
& PLS & $9.62 .10^{-3}$ & $3.4 .10^{-2}$ \\
r & PCR & 1.0000 & 0.9999 \\
& PLS & 1.0000 & 0.9996 \\
Intercept & PCR & $7.10^{-5}$ & 0.0025 \\
& PLS & 0.0001 & 0.0016 \\
Slope & PCR & 1.0000 & 0.9994 \\
& PLS & 1.0000 & 0.9996 \\
\hline
\end{tabular}

Accuracy and precision for the analysis of ROS and EZE substances in the prepared synthetic mixtures at three different concentration levels $(0.64,0.96$ and $1.28 \mathrm{~g} / \mathrm{mL}$ for EZE and $0.48,0.72$ and $0.96 \mathrm{~g} / \mathrm{mL}$ for ROS) in intra-day $(\mathrm{n}=6)$ and inter-day $(\mathrm{n}=6)$, was tested for the applicability of the proposed chemometric methods. The calculated results for percent relative error, standard deviation and relative standard deviation were presented in table 4 and 5. Good accuracy and precision were observed for the results obtained by PCR and PLS calibrations. 
AKTAŞ et al. / Spectrometric Determınatıon of Rosuvastatin And Ezetimibe in Tablets by Multivailate Cailbration Approach

Table 4. Accuracy and precision results for PCR

\begin{tabular}{|c|c|c|c|c|c|c|c|c|c|c|c|}
\hline \multicolumn{2}{|c|}{ Added $(\mu \mathrm{g} / \mathrm{ml})$} & \multicolumn{5}{|c|}{ EZE } & \multicolumn{5}{|c|}{ ROS } \\
\hline EZE & ROS & Found & SD & $\%$ BSS & $\%$ RE & Recovery(\%) & Found & SD & $\%$ BSS & $\% \mathrm{RE}$ & Recovery(\%) \\
\hline $0 ., 64$ & 0.48 & 0.64023 & $2.94 \mathrm{E}-03$ & 2.94E-05 & 0.03592 & 100.0359 & 0.481268 & $3.98 \mathrm{E}-02$ & 3.97E-04 & 0.264213 & 100.2642 \\
\hline 0.96 & 0.72 & 0.960256 & 2.99E-04 & 2.99E-06 & 0.026631 & 100.0266 & 0.721314 & $4.54 \mathrm{E}-02$ & $4.53 \mathrm{E}-04$ & 0.182444 & 100.1824 \\
\hline 1.28 & 0.96 & 1.280282 & $5.81 \mathrm{E}-04$ & $5.81 \mathrm{E}-06$ & 0.022062 & 100.0221 & 0.961344 & $3.16 \mathrm{E}-02$ & $3.16 \mathrm{E}-04$ & 0.140019 & 100.14 \\
\hline & & & & & $\overline{\mathbf{x}}$ & 100.0282 & & & & $\overline{\mathbf{x}}$ & 100.1956 \\
\hline & & & & & SD & 0.007062 & & & & SD & 0.063127 \\
\hline & & & & & BSS & 7.06E-05 & & & & BSS & 0.00063 \\
\hline & & & & & LOD & 0.023302 & & & & LOD & 0.208299 \\
\hline & & & & & LOQ & 0.070612 & & & & LOQ & 0.631208 \\
\hline
\end{tabular}

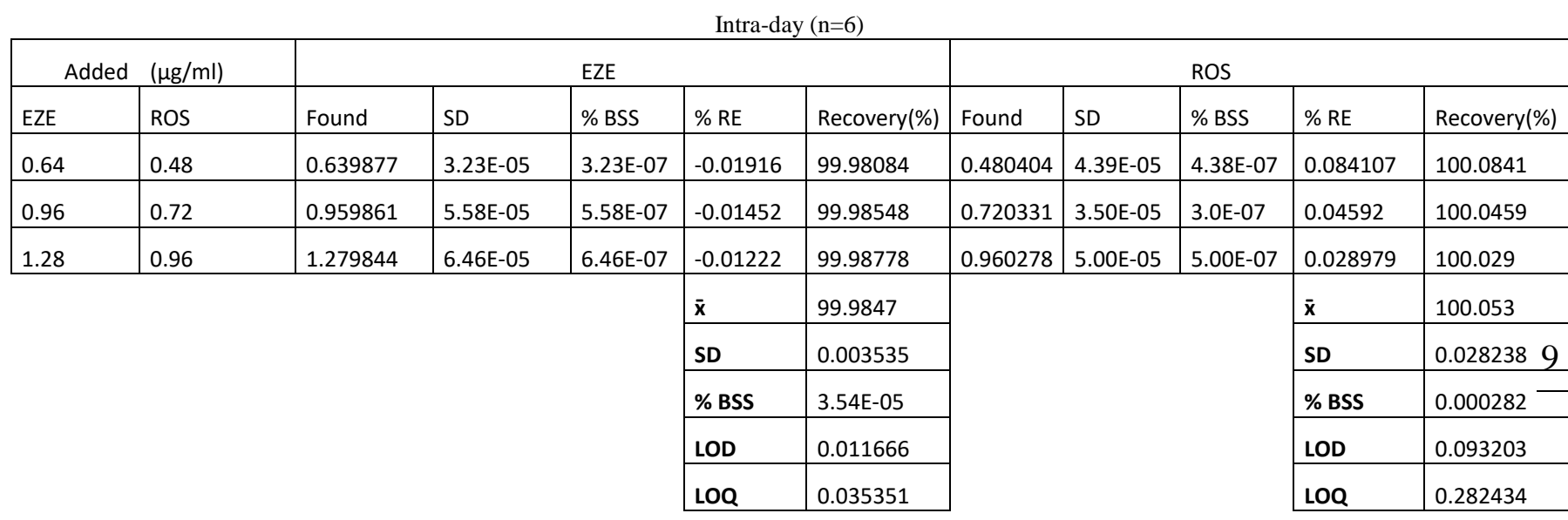

SD: Standard deviation, RE: Percent relative error

Table 5. Accuracy and precision results for PLS

\begin{tabular}{|c|c|c|c|c|c|c|c|c|c|c|c|}
\hline \multicolumn{12}{|c|}{ Inter-day $(n=6)$} \\
\hline \multicolumn{2}{|c|}{ Added $(\mu \mathrm{g} / \mathrm{ml})$} & \multicolumn{5}{|c|}{ EZE } & \multicolumn{5}{|c|}{ ROS } \\
\hline EZE & ROS & Found & SD & $\%$ BSS & $\% \mathrm{RE}$ & Recovery(\%) & Found & SD & $\%$ BSS & $\%$ RE & Recovery(\%) \\
\hline 0.64 & 0.48 & 0.640119 & $1.00 \mathrm{E}-03$ & $1.00 \mathrm{E}-05$ & 0.018659 & 100.0187 & 0.479889 & 0.087302 & $8.72 \mathrm{E}-04$ & -0.02302 & 100.0729 \\
\hline 0.96 & 0.72 & 0.959843 & 7.00E-04 & 7.00E-06 & -0.01634 & 99.98366 & 0.719971 & 0.033081 & 3.31E-04 & -0.00403 & 99.93277 \\
\hline \multirow[t]{6}{*}{1.28} & 0.96 & 1.279961 & 7.72E-04 & 7.72E-06 & -0.00303 & 99.99697 & 0.960427 & 0.064689 & $6.47 \mathrm{E}-04$ & 0.044474 & 99.99183 \\
\hline & & & & & $\overline{\mathbf{x}}$ & 99.99976 & & & & $\overline{\mathbf{x}}$ & 99.97605 \\
\hline & & & & & SD & 0.017666 & & & & SD & 0.070367 \\
\hline & & & & & BSS & 0.000177 & & & & BSS & 0.000704 \\
\hline & & & & & LOD & 0.058297 & & & & LOD & 0.232212 \\
\hline & & & & & LOQ & 0.176659 & & & & LOQ & 0.703673 \\
\hline
\end{tabular}




\begin{tabular}{|c|c|c|c|c|c|c|c|c|c|c|c|}
\hline \multicolumn{12}{|c|}{ Intra-day $(n=6)$} \\
\hline \multicolumn{2}{|c|}{ Added $(\mu \mathrm{g} / \mathrm{ml})$} & \multicolumn{5}{|c|}{ EZE } & \multicolumn{5}{|c|}{ ROS } \\
\hline EZE & ROS & Found & SD & $\%$ BSS & $\%$ RE & Recovery(\%) & Found & SD & $\%$ BSS & $\%$ RE & Recovery(\%) \\
\hline 0.64 & 0.48 & 0.640051 & 7.29E-02 & 7.29E-04 & 0.007975 & 100.008 & 0.479889 & 0.153317 & 0.001534 & -0.02302 & 99.97698 \\
\hline 0.96 & 0.72 & 0.959954 & 2.03E-04 & 2.03E-06 & -0.00482 & 99.99518 & 0.719971 & 0.050142 & 0.000501 & -0.00403 & 99.99597 \\
\hline 1.28 & 0.96 & 1.279951 & $6.12 \mathrm{E}-02$ & $6.12 \mathrm{E}-04$ & -0.00386 & 99.99614 & 0.960427 & 0.083267 & 0.000832 & 0.044474 & 100.0445 \\
\hline & & & & & $\overline{\mathbf{x}}$ & 99.99976 & & & & $\overline{\mathbf{x}}$ & 99.97605 \\
\hline & & & & & SD & 0.007127 & & & & SD & 0.034808 \\
\hline & & & & & BSS & 7.13E-05 & & & & BSS & 0.000348 \\
\hline & & & & & LOD & 0.023518 & & & & LOD & 0.114867 \\
\hline & & & & & LOQ & 0.071268 & & & & LOQ & 0.348083 \\
\hline
\end{tabular}

The linear regression analysis of the added concentration and the concentration found in the synthetic mixtures were realized for each drug and for each calibration technique. In this regression analysis, the correlation coefficient (r), intercept, slope and relative standard deviation values were found satisfactory for the proposed chemometric techniques in Table 3 . As can be seen, all the statistic values indicated that all techniques are convenient for the determination of two drugs in synthetic mixtures.

A summary of the assay results for the pharmaceutical formulation is given Table 6 . The results of all methods were very to each other as well as to the label value of commercial drug formulation.

Table 6. Assay results for the pharmaceutical formulation (mg/tablet)

\begin{tabular}{lll}
\hline Drug & PCR & PLS \\
\hline EZE & & \\
Mean \pm SD* & $9.928 \pm 0.02$ & $10.017 \pm 0.02$ \\
ROS & & \\
Mean \pm SD* & $10.00 \pm 0.36$ & $10.06 \pm 0.54$
\end{tabular}

Results obtained are average of six experiments for each technique.

*SD: Standard deviation * 


\section{CONCLUSIONS}

Two chemometric technique in spectrometric analysis, PCR and PLS, were proposed for the simultaneous determination of EZE and ROS in their binary mixtures. These techniques were applied with great success to two commercial pharmaceutical tablets. The resolution of highly overlapping drug mixtures was achieved by the use of PCR and PLS techniques. A selection of working wavelength having high correlation values with concentration due to interference coming from matrix sample or additional analytes outside the working range. According to the obtained results, it was observed that the PCR method gave more accurate results than the PLS method in this combination of two drugs. The proposed chemometric techniques can be applied for the routine analysis of two drugs in the tablet formulation without any a priori chemical separation and without time consuming.

\section{Acknowledgment}

This research work has been supported by research grants from Süleyman Demirel University Scientific Research Project 5012-YL1-17. 


\section{REFERENCES}

ALZOMAN, N.Z, SULTAN, M., MAHER, H., et al., 2013, Analytical study for the chargetransfer complexes of rosuvastatin calcium with pi-acceptors. Molecules, 18, 7711 7725 .

BELUDARI, M.I., PRAKASH, K.V., MOHAN, G.K., 2013, RP-HPLC method for simultaneous estimation of rosuvastatin and ezetimibe from their combination tablet dosage form. Int. J. Chem Anal Sci., 4(4):205 - 209.

CAMPO, V.L., CARVAlHO, I., 2007, Estatinas hipomemicas e novas tendencias terapeuticas. Quim Nova., 30(2):425 - 430.

EL-BAGARY, R.I., ELKADY, E.F., KADRY, A.M., 2012, Spectrofluorimetric determination of certain antihyperlipidemic agents in bulk and pharmaceutical preparations. Spectroscopy: Int J., 27(2):83 - 92.

KOSOĞLU, T., STATKEVİCH, P., YANG, B., SURESH, R., CUTLER, D.L., 2004, Pharmacodynamic interaction between ezetimibe and rosuvastatin. Curr. Med. Res. Opin., 20(8): 1185 - 1195.

LINGESWARA, R. P., PRASAD, R.S., GANESH, M., SARAVANAN, V.S., SIVA, K.T., 2006, Simultaneous estimation of simvastatin and ezetimibe in combined dosage forms by RP-HPLC method. Proceedings of the 58th Indian Pharmaceutical Congress, Mumbai, India, p.259.

RAMADAN, A.A., MANDIL, H., GHAZAL, N., 2014, Spectrophotometric determination of rosuvastatin calcium in pure form and pharmaceutical formulations by the oxidation using iodine and formation triiodide complex in acetonitrile. Int J Pharm Sci. 6(5):579 -585 .

RAMADAN, A.A., MANDIL, H., GHAZAL, N., 2015, Differential pulse polarographic behavior and determination of rosuvastatin in pure form and in pharmaceutical preparations using a static mercury drop electrode. Int J Pharm Sci. 7(1):771 - 780.

SHIVSHANKAR, K., SREEKANTH, N., et al, 2007, Validated simultaneous estimation of simvastatin and ezetimibe by RP-HPLC in pure and pharmaceutical dosage form. Asian J Chem., 19(6):4303 - 4308.

SISTLA, R.M., TATA, V.S., et al., 2005, Development and validation of a reversed phase HPLC method for the determination of a ezetimibe in pharmaceutical dosage form. $\mathrm{J}$. Pharm. Bio. Med. Anal., 39(3-4):517 - 522.

WANI, T.A., DARWISH, I.A., KHALIL, N.Y., 2013, Novel microwell-based spectrophotometric assay for the determination of rosuvastatin calcium in its pharmaceutical formulations. Curr Pharm Anal., 9(1):54 60.BIOSHIP, E., HUSSEIN, W.,1984, Electroanalytical study of tricyclic antidepressants, Analyst, 109, 73-80. 